1-ORIGINAL ARTICLES

\title{
Vasoplegic endothelial dysfunction in orthotopic liver transplantation
}

Paulo Roberto Barbosa Evora ${ }^{I}$, Orlando de Castro e Silva Júnior II

DOI: http://dx.doi.org/10.1590/S0102-86502016001300001

IFull Professor, Department of Surgery and Anatomy, Ribeirão Preto Medical School, University of São Paulo, Ribeirão Preto, São Paulo, Brazil. IIFull Professor, Department of Surgery and Anatomy, Ribeirão Preto Medical School, University of São Paulo, Ribeirão Preto, São Paulo, Brazil. 
After graft reperfusion in liver transplantation, ischemic reperfusion syndrome (IRS) is characterized by persistent hypotension with low systemic vascular resistance. This syndrome is like a $30 \%$ decrease in mean arterial pressure (MAP) and occurs within $5 \mathrm{~min}$ of reperfusion of the graft and lasts at least $1 \mathrm{~min}$. Hypotension associated with low systemic vascular resistance (SVR) can persist for an hour or more. The severity of the IRS is probably the result of both and contribute to impaired liver function after surgery and primary graft failure.

Mass production of NO by inducible isoform of NO synthase (iNOS) is considered responsible for the profound vasodilatation and myocardial dysfunction in septic shock. The role of NO in IRS in liver transplantation is not known. The number of liver transplantation procedures is increasing worldwide. The ischemia and reperfusion syndrome observed during liver transplantation surgery may manifest itself as a state of vasoplegia which often require vasopressor support to maintain stable hemodynamics. Occasionally, the conventional treatment for this vasoplegic syndrome (VS) (e.g., phenylephrine, norepinephrine, and vasopressin) is not sufficient to restore adequate systemic vascular resistance (SVR) and systemic pressure support. These data, although incipient, motivated the present editorial.

The syndrome of ischemia-reperfusion (IRS) resulting in hypotension and increase in transaminases postoperatively in most patients undergoing the liver transplant and, in severe cases, this can lead to graft failure and death. After reperfusion of the graft, there is a decrease in MAP and SVR and an increase in cardiac index (CI), which often lasts for one to two hours. Some patients have reduced myocardial contractility. The precise mechanisms underlying these hemodynamic responses are not known.

Some authors have reported an increase in nitrite levels in patients with cirrhosis, but not in non-cirrhotic patients. A posthoc analysis based on these reports showed that the nitrite levels were elevated in patients with cirrhosis. There was a decrease in nitrite levels after use in the MB group cirrhosis, but not in the noncirrhotic group. This suggests that different pathways for NO production may be involved in cirrhotic and non-cirrhotic patients

Methylene blue dye (MB) has been used as a vasopressor in sepsis and acute liver failure When these conditions are associated with low MAP, an intravenous bolus AM increases MBP by an increase in SVR and some cases, cardiac index (IC). Sepsis and SRI show hemodynamic and biochemical similarities, including increasing standards of pro-inflammatory cytokines. In sepsis, these changes are associated with excess nitric oxide (NO). The AM acts, reducing the action of NO by inhibition of guanylate cyclase, the enzyme target node.
In several previous studies, it is in doses of 1 to $3 \mathrm{mg} /$ $\mathrm{kg}$ caused hemodynamic improvement in sepsis and acute liver failure. The dose 1.5 to $3 \mathrm{mg} / \mathrm{kg}$ is, as proposed by British National Formulary. Most clinical trials in sepsis failed to demonstrate a change in IC, although, in clinical practice, the hyperdynamic state situation is the observed increase in MAP and SVR to match better the IC at lower levels. Several MB modes of action have been postulated. Different mechanisms may predominate in different clinical situations. The MB has properties such as blocking agent of NO proven by both the inhibition of guanylate cyclase. It also acts as an anti-oxidant, pro-oxidant inhibits the synthesis of prostacyclin, and accelerates reductive processes in the cell.

There is clinical experience with MB is not new in liver transplant. Because of the most important technical literature, thirty-six patients undergoing elective liver transplantation were randomized to receive an $\mathrm{MB}$ intravenous bolus $(1.5 \mathrm{mg} /$ $\mathrm{kg}$ ) before reperfusion of the graft, or saline (placebo). In this study, KOELZOW and colleagues (2002) recorded hemodynamic variables, postoperative liver function tests, and time to hospital discharge. The MB group had higher average blood pressure, increased heart rate, and less need for epinephrine. The results of this study show that MB attenuates hemodynamic changes of IRS in transplant acting through inhibition of guanylate cyclase. In the KOELZOW experience, MB was used before the perfusion of the transplanted liver or is used for the prevention of ischemiareperfusion syndrome.

The first MB use as an agent for the pharmacological treatment of the vasoplegic syndrome during liver transplant surgery has recently been reported in a male 61-year-old patient underwent liver and kidney transplant by lightning hepatorenal insufficiency secondary to autoimmune hepatitis. After reperfusion of the graft, the patient became hypotensive and required several bolus of calcium chloride, sodium bicarbonate, norepinephrine, and epinephrine. Shortly after that, a vasopressin infusion (4 $\mathrm{U} / \mathrm{h}$ ) was started for additional support of blood pressure, causing only a minor hemodynamics improvement. Because the set of hemodynamic data suggested VS, an MB loading dose was initiated ( $2 \mathrm{mg} / \mathrm{kg}$ over 30 minutes), followed by a maintenance infusion for 6 hours $(0.5 \mathrm{mg} / \mathrm{kg} / \mathrm{h})$. Shortly after the beginning of the $\mathrm{MB}$, there was a significant improvement in hemodynamic allowing interruption of weaning and subsequent infusion of norepinephrine and vasopressin. Blood pressure remained stable at around $100 / 60 \mathrm{mmHg}$, with only minimal vasoactive amines support for the rest of the process (epinephrine, $0.05 \mathrm{ug} / \mathrm{kg} / \mathrm{min}$ ). It must once again emphasize that the MB is not a vasopressor drug. In fact, by blocking of cGMP system it enhances the action of the 
amines in a kind of crosstalk with the cAMP system linked to the adrenergic system.

Liver transplantation is a surgical treatment option for patients with hepato-pulmonary syndrome; once medical treatments to date have been disappointing. These unsatisfactory outcomes have been accompanied by many studies using various pharmaceutical agents such as indomethacin, almitrine, octreotide and garlic, which is not shown consistently positive effects. Thus, the use of MB should be considered, and may provide a new approach for long-term treatment strategies.

\section{References}

1. CaoZ, GaoY,TaoG. Vasoplegic syndromeduringlivertransplantation. Anesth Analg. 2009;108(6):1941-3. PMID:19448226.

2. Evora PR, Alves Junior L, Ferreira CA, Menardi AC, Bassetto S, Rodrigues AJ, Scorzoni Filho A, Vicente WV. Twenty years of vasoplegic syndrome treatment in heartsurgery. Methylene blue revised. Rev Bras Cir Cardiovasc. 2015;30(1):84-92. PMID:25859872.

3. Evora PR, Ribeiro PJ, Vicente WV, Reis CL, Rodrigues AJ, Menardi AC, Alves Junior L, Evora PM, Bassetto S. Methylene blue for vasoplegic syndrome treatment in heart surgery: fifteen years of questions, answers, doubts and certainties. Rev Bras Cir Cardiovasc. 2009;24(3):279-88. PMID:20011872.

4. Evora PR, Celotto AC, Capellni VK. Disfunção endotelial vasoplégica e choque circulatório. Primeira Edição, Ed Atheneu, Rio de Janeiro, Brazil, ISBN: 8538802097, ISBN13: 9788538802099.

5. Fischer GW, Bengtsson Y, Scarola S, Cohen E. Methylene blue for vasopressor-resistant vasoplegia syndrome during liver transplantation. J Cardiothorac Vasc Anesth. 2010;24(3):463-6. PMID: 18835528.

6. Koelzow H, Gedney JA, Baumann J, Snook NJ, Bellamy MC. The effect of methylene blue on the hemodynamic changes during ischemia reperfusion injury in orthotopic liver transplantation. Anesth Analg. 2002;94(4):824-9. PMID: 11916779.3.

7. Roma J, Balbi E, Pacheco-Moreira L, Gonzalez AC, Leal CG, Pousa F, Zynger I, Leite D, Halpern M, Guerra PP, Covelo M, Carius L, Agoglia L, Oliveira A, Enne M. Methylene blue used as a bridge to liver transplantation postoperative recovery: a case report. Transplant Proc. 2010;42(2):601-4. PMID: 20304203.

8. Rosique RG, Rosique MJ, Rosique IA, Tirapelli LF, Castro e Silva O Jr, dos Santos JS, Evora PR. Effect of methylene blue on the hemodynamic instability resulting from liver ischemia and reperfusion in rabbits. Transplant Proc. 2011;43(10):3643-51. PMID:22172820.

9. Thevenot T, Pastor CM, Cervoni JP, Jacquelinet C, Nguyen-Khac E, Richou C, Heyd B, Vanlemmens C, Mantion G, Di Martino V, Cadranel J. [Hepatopulmonary syndrome]. Gastroenterol Clin Biol. 2009;33(6-7):565-79. PMID:19481392.

10. Weinbroum AA, Paret G, Szold O, Rudick V, Krupitzky L. Selective attenuation of acute lung ventilatory injury by methylene blue after liver ischemia-reperfusion: a drug response study in an isolated perfused double organ model. Transplantation. 2001;72(3):385-92. PMID: 11502965. 